\title{
ABORDAGEM CARISMÁTICA E TRANSFORMACIONAL: MODELOS CONCEPTUAIS E CONTRIBUTOS PARA O EXERCÍCIO DA LIDERANÇA
}

\author{
António Rui Gomes ${ }^{1}$ \\ José $\mathrm{Cruz}^{2}$
}

Resumo: Neste artigo apresentamos uma revisão de literatura acerca da abordagem carismática e transformacional do estudo da liderança, procurando analisar os seus conceitos principais e os modelos conceptuais mais representativos. De igual modo, analisamos as possibilidades de aplicação desses contributos ao exercício da liderança, ajudando na compreensão dos processos inerentes à relação entre o líder e os membros do grupo. Por último, descrevemos alguns resultados obtidos até agora no estudo de líderes com características carismáticas e transformacionais.

Palavras-chave: Liderança. Habilidades sociais. Comportamento coletivo.

As investigações e os modelos explicativos acerca da liderança permitemnos verificar diferentes orientações e influências considerando-se, hoje em dia, a existência de abordagens teóricas com determinados pressupostos e premissas que as tornam distintas. Neste sentido, são habitualmente aceites três paradigmas principais na conceptualização deste tema: um centrado no estudo dos traços de personalidade, outro interessado na observação dos comportamentos assumidos pelos líderes no exercício das suas funções e o terceiro que chama a atenção para as variáveis situacionais que influenciam a eficácia da liderança (Vecchio, 1995). No primeiro caso, a preocupação foi tentar identificar e caracterizar os atributos pessoais dos que exerciam posições de chefia, de forma a estabelecer os padrões de personalidade que distinguiam os líderes dos que não o eram. No segundo movimento, o foco de interesse centrou-se na análise daquilo que os responsáveis

1 Professor do Instituto de Educação e Psicologia, Universidade do Minho - Portugal. E-mail: rgomes@iep.uminho.pt

2 Professor do Instituto de Educação e Psicologia, Universidade do Minho - Portugal. 
faziam no normal desenrolar das suas funções, procurando-se determinar os comportamentos que mais se correlacionavam com a eficácia obtida. Na última perspectiva, seguiu-se uma lógica mais contingencial, privilegiando-se a observação dos factores do ambiente que podiam condicionar decisivamente a liderança. Convém, no entanto, esclarecer que alguns dos modelos resultantes deste último movimento também são apelidados de "interaccionistas", pois, apesar de enfatizarem a necessidade de os líderes se adaptarem às exigências contextuais, acabaram por incluir aspectos relacionados com as características de personalidade e os comportamentos considerados mais eficazes. É neste sentido que Yukl (1989) afirma que essa proposta pode ser entendida de duas formas distintas privilegiando, por um lado, a compreensão dos factores e exigências externas que influenciam a liderança e, por outro lado, tentando determinar os aspectos situacionais que moderam a relação entre os traços de personalidade e os comportamentos associados à eficácia atingida no trabalho.

Apesar de os modelos e investigações acerca da liderança abundarem, a verdade é que a década de 1980 iniciou-se com um certo pessimismo relativamente ao estudo desse tema, pois, se por um lado existiam bastantes propostas explicativas acerca da eficácia dos líderes e das meIhores estratégias a utilizar na adaptação a diferentes contextos profissionais, por outro, os dados não eram nada animadores quanto a resultados consensuais, não só dentro de cada um dos modelos e teorias, que estavam constantemente a ser contrariados, mas também nas várias abordagens ao estudo desse fenómeno. Daí que, como refere Bryman (1992), tenham sido avançadas novas propostas que tentaram lutar contra esse desânimo, integrando princípios e pressupostos de distintos autores, mesmo dos mais clássicos, como são os defensores dos traços de personalidade.

É nessa lógica que surge a teoria da liderança carismática de House (1977), a teoria da liderança transformacional e transaccional de Bass (1985) e Burns (1978), a teoria atribucional da liderança carismática de Conger e Kanungo (1987) e as teorias da liderança visionária desenvolvidas por diversos grupos de autores (ver Bennis \& Nanus, 1985; Kouzes \& Posner, 1987; Sashkin, 1988). O que existia de comum entre todas essas conceptualizações era o interesse pelo estudo de líderes históricos e gestores de grandes organizações que conseguiram obter excelentes resultados no seu trabalho, mesmo quando se encontravam perante situações de crise e de grande concorrência externa. Como refere Rego (1998), as últimas duas décadas são dominadas por esse novo movimento que se interessa pelo carisma e a capacidade transformacional dos líderes na relação com os colaboradores, existindo a preocupação em integrar os aspectos comportamentais e os traços de personalidade assim como o 
tipo de interacções que se estabelecem entre todos os membros do grupo/organização.

É centrado nesta última abordagem que organizamos este artigo, procurando distribuir a informação em torno de duas áreas distintas. Por um lado, propomos um entendimento dos conceitos-chave e modelos teóricos avançados pelos principais autores desse novo movimento, bem como uma breve descrição dos resultados obtidos nas investigações levadas a cabo. Numa segunda parte, efectuamos uma reflexão acerca das possíveis aplicações ao contexto desportivo, analisando a relevância dos pressupostos teóricos, o contributo dado na melhoria do estudo da relação treinador-atleta e, por último, apontamos brevemente os estudos entretanto efectuados à luz dessa perspectiva.

\section{A Importância do carisma}

Essas novas orientações no estudo da liderança têm em comum o facto de analisarem as características apresentadas por líderes que conseguiram obter resultados excepcionais através das suas acções. Um dos primeiros conceitos avançados para essa discussão foi o carisma, tendo sido sugerido pelo sociólogo Weber $(1964,1968)$ como podendo ajudar a caracterizar as grandes personalidades mundiais que contribuíram para mudar o curso da história. O termo carisma teve a sua origem na antiga Grécia, sendo entendido como um "dom" atribuído a figuras mitológicas, servindo para justificar os acontecimentos que não tinham uma explicação lógica. Mais tarde, o termo foi adoptado pela religião católica, descrevendo determinados talentos humanos, como sejam, as profecias, a sabedoria e a arte de curar, que eram capacidades concedidas por Deus a algumas pessoas que passavam a possuir "o dom da graça".

Partindo dessa análise, Weber questionou a possibilidade de o carisma não fazer apenas parte do domínio religioso e poder também ajudar a compreender o sucesso e o impacto social das grandes individualidades. Para o autor, o carisma seria apanágio de alguém que, perante uma situação complicada, conseguiu reunir à sua volta um conjunto de indivíduos que acreditaram nas suas capacidades para apontar o meIhor caminho a seguir, encarando-o como uma pessoa "visionária" e inspiradora de valores fundamentais.

Um dado desde logo a ter em conta neste entendimento é o facto de se considerar a necessidade da existência de um determinado contexto de mudança e turbulência como factores essenciais para a emergência do líder carismático. Compreendendo assim o termo, percebe-se melhor o facto de ser em tempos de crise, quando se questionam os valores e os ideais pessoais e sociais, que os indivíduos carismáticos mais se podem afirmar, pois, ao apelarem para novos princípios e processos de 
resolução dos problemas, ganham mais facilmente o entusiasmo e a dedicação dos outros (Aaltio-Marjosola \& Takala, 2000).

Um outro aspecto fundamental a ponderar é o facto de o conceito não dever ser apenas focalizado no "dom" possuído pelo líder, mas também na forma como ele é percepcionado pelos outros, levando-os a comprometerem-se com as suas ideias e acções. Quer isto dizer que não adianta analisarmos a figura carismática se não soubermos aquilo que, do ponto de vista dos liderados, despertou o interesse e a vontade em seguir essa pessoa.

O significado atribuído ao carisma veio então suscitar a atenção dos autores, podendo ser-lhes apontado como ponto comum o acordo acerca da importância desse "dom" na compreensão dos comportamentos dos líderes excepcionais. É neste sentido que Fiol (1999) inclui todas as propostas surgidas a partir dos finais dos anos 1970 num novo paradigma, designado por liderança neo-carismática. E são várias as razões para essa generalização. Em primeiro lugar, todos os modelos partiIham a convicção de Weber de que só devemos falar em indivíduos carismáticos se estivermos na presença de alguém que:i) conseguiu formular uma nova visão do trabalho, partindo dos valores e normas ideológicas existentes no seu grupo ou organização de referência; ii) apresentou soluções e estratégias inovadoras para resolver problemas significativos; iii) está disponível para introduzir mudanças radicais e pouco conservadoras e iv) tende a destacar-se em momentos de maior pressão e crise existentes no contexto social. Em segundo lugar, todos os autores valorizam a compreensão das variáveis que tornam essa pessoa "única", tais como a sua capacidade visionária ou inspiradora, a tendência para apelar a valores importantes, as mudanças introduzidas no funcionamento dos outros etc. A terceira aproximação prende-se com o interesse pela vertente emocional e afectiva da relação entre líder e liderados, manifestada através da identificação que estes últimos apresentam relativamente às ideias e metas definidas. O quarto ponto comum é representado pela convicção de que as organizações que são dirigidas por pessoas carismáticas, transformacionais ou visionárias (consoante as teorias), quando comparadas com outros locais sem esse tipo de profissionais, conseguem obter uma mudança positiva, tanto nos membros do grupo como na performance final. É precisamente isto que demonstram os estudos sobre os efeitos diferenciais dos líderes carismáticos e não carismáticos, apontando para a obtenção de níveis superiores de rendimento dos primeiros, tanto nos indivíduos com quem contactam directamente, como nos resultados obtidos na organização a que pertencem (ver Howell \& Frost, 1989; Shamir, House \& Artur, 1993; Shea, 1999). Finalmente, o autor acredita que o facto de essas teorias assumirem como fulcral a importância do carisma, que era um dos conceitos-chave da li- 
teratura no domínio da Sociologia, acaba por reflectir-se numa certa parcimónia entre todas elas.

\section{Os principais modelos carismáticos e transformacionais da liderança}

\section{O modelo de liderança carismática}

Uma das primeiras tentativas de estruturar os dados e pressupostos acerca da liderança carismática num único modelo foi efectuada por House (1977). O interesse desse autor traduziu-se pelo formular de um conjunto de hipóteses sobre as características e comportamentos dos líderes carismáticos que ajudavam a explicar a adaptação a diferentes situações, bem como a eficácia obtida nas funções exercidas. Neste sentido, foram apresentados não só os comportamentos associados à liderança carismática, mas também alguns traços de personalidade e variáveis situacionais que explicavam o surgimento de indivíduos carismáticos.

No que diz respeito aos aspectos mais pessoais, foram apontados os seguintes atributos de personalidade: níveis elevados de auto-confiança, tendência para dominar as relações com os outros, necessidade de influenciar o pensamento das outras pessoas e uma grande convicção acerca da virtude das suas ideias e padrões morais.

Quanto aos comportamentos, o autor descreveu um conjunto de estratégias destinadas a aumentar a percepção de carisma pelos membros do grupo. Uma primeira solução sugere a necessidade de os responsáveis se assumirem como modelos a seguir, demonstrando um conjunto de valores e princípios que são representadores do seu carisma, procurando torná-los apelativos para todos. Em segundo lugar, e como forma de promover a aceitação das suas ideias, devem adoptar acções que aumentem a percepção de confiança e admiração, transmitindo uma imagem de competência e de sucesso. De igual modo, devem expressar ideais ("visão") que congreguem o pensamento dos elementos do grupo, promovendo a coesão no seio da equipa de trabalho. $O$ terceiro domínio refere-se às aspirações e expectativas exteriorizadas pelo líder relativamente às capacidades de todos os colaboradores, sendo sinais de carisma a manifestação de uma atitude de optimismo em face da possibilidade de os esforços do grupo poderem, no final, equivaler à realização dos objectivos traçados. Finalmente, o responsável também deve ser capaz de formular motivos para a execução das tarefas. Neste caso, podem ser apontadas como estratégias essenciais a estimulação do orguIho de pertença ao grupo, o aumento da confiança na possibilidade de 
se ultrapassarem as dificuldades colocadas por outros concorrentes ou rivais da mesma área de actividade e a promoção de uma atitude de desafio no sentido de os outros acreditarem que são capazes de atingir padrões de excelência no trabalho.

No que respeita aos factores contextuais, o autor avançou um pressuposto central que veio a ser utilizado por outros modelos formulados posteriormente, defendendo a maior facilidade dos líderes carismáticos em emergir em momentos de crise e de maior pressão exercida sobre as organizações. Nessas situações, as características de personalidade e os comportamentos do responsável parecem ajustar-se mais eficazmente, aumentando a probabilidade de serem percepcionados como carismáticos.

Mais recentemente, durante a década de 1990, o modelo acabou por sofrer algumas alterações, denotando-se uma preocupação evidente em enfatizar os aspectos organizacionais e grupais, bem como em atribuir uma maior importância aos indicadores de eficácia baseados na performance final atingida (ver Shamir, House, \& Arthur, 1993).

Os autores passaram a assumir que, para compreendermos melhor os resultados produzidos pelo líder carismático, deveríamos analisar as transformações introduzidas no nível do auto-conceito dos membros do grupo. Assim, aquilo que tipifica melhor as suas acções é a capacidade para estabelecer uma relação entre a identidade dos colaboradores (autoconceito) e os objectivos estabelecidos, ao ponto de a missão que o grupo se propõe alcançar se tornar um aspecto valorizado ao nível do autoconceito de todos os envolvidos.

As estratégias utilizadas pelo líder para obter essa transformação podem ser de quatro tipos. Assim, ele deve começar por alterar a forma como o trabalho é encarado, tornando-o o mais significativo e importante possível. Neste caso, não se preconiza a utilização da motivação extrínseca como método de promoção do interesse pelo trabalho, defendendo-se antes a motivação intrínseca, encorajando-se os elementos do grupo a desenvolverem as suas potencialidades, procurando-se assim aumentar os sentimentos de realização profissional. A segunda estratégia aponta a necessidade de existir uma visão do trabalho apelativa e estimulante, baseada na convicção de um futuro melhor para todos, em que as pessoas se sintam bem nas funções que exercem. A terceira área de acção remete para a promoção dos sentimentos de identidade colectiva, devendo-se realçar as particularidades existentes nos objectivos partilhados pela equipa de trabalho que são distintos dos valores e práticas que caracterizam outros grupos. A última opção implica o reforço dos sentimentos de auto-eficácia individuais e colectivos, através da definição de planos de trabalho que sejam exequíveis e realistas, bem como demonstrando uma atitude de optimismo em face da possibilidade de as capacidades dos indivíduos e do grupo resultarem no alcance das metas estabelecidas. 
Os efeitos dessas acções fazem-se obviamente sentir no grau de envolvimento dos sujeitos relativamente à visão do líder, passando a estar mais disponíveis para fazerem sacrifícios pessoais em nome de um ideal colectivo e evidenciando uma maior auto-estima e bem-estar decorrentes das realizações colectivas. Se o processo se desenvolver desse modo, então percebemos de que forma as estratégias utilizadas poderão acabar por ter um efeito mais global no grupo, aproximando as aspirações individuais de uma identidade colectiva partilhada no seio das equipas de trabalho e na própria organização.

No entanto, e apesar de as reformulações do modelo serem relativamente recentes, a verdade é que a inclusão da dimensão do auto-conceito não tem, para já, dado grandes indicações acerca da sua validade enquanto factor explicativo do surgimento e eficácia dos líderes carismáticos (ver Shamir, Zakay, Breinin, \& Popper, 1998).

\section{O modelo comportamental e atribucional da liderança carismática}

Conger e Kanungo desenvolveram esse modelo em 1987, efectuando uma revisão de alguns dos pressupostos em 1998. Um dos primeiros aspectos essenciais para compreendermos essa proposta é o facto de os autores conceberem o carisma como uma dimensão perfeitamente observável, tal como eram as vertentes mais tradicionais do estudo da liderança (ex:consideração individual, valorização da tarefa,comportamentos autocráticos e democráticos). Em termos práticos, aquilo que se pretendeu evitar foi a identificação do conceito como um traço de personalidade, o que limitaria, em muito, a futura formação de profissionais nessa área. Uma segunda premissa básica prende-se com a afirmação de que o carisma existe a partir das atribuições efectuadas por aqueles que se relacionam, directa ou indirectamente, com o líder. É neste sentido que os processos de influência se tornam vitais para podermos identificar indivíduos carismáticos, pois essa característica deve ser concebida como o reconhecimento efectuado pelos elementos que fazem parte do grupo/organização, podendo ser estudada como qualquer outra dimensão da liderança. Deste modo, Conger e Kanungo $(1988,1998)$ entendem a liderança como um processo que envolve a mudança dos membros da organização de um determinado estado para um outro nível de desenvolvimento que é consonante com uma "visão" assumida pelo responsável. Já o conceito de "visão" deve ser definido como uma "imagem mental" reproduzida pelo líder para evocar uma dada construção sobre o futuro do grupo ou da organização (Conger, 1989).

O processo através do qual se dá a implementação dessa ideia pode ser repartido em três fases distintas, que englobam um conjunto de comportamentos do responsável relativamente aos colaboradores. 
A primeira etapa é caracterizada pela avaliação do contexto externo e das características dos colaboradores. Assim, o líder deve começar por observar a situação onde se vai integrar, pois a existência de oportunidades por explorar ou níveis de rendimento abaixo do desejável podem, obviamente, constituir domínios de intervenção e de formulação de uma nova "visão" do trabalho. A partir do momento em que existe um conhecimento adequado das contingências a enfrentar, deve procurar aferir os recursos disponíveis para lidar com os constrangimentos colocados à implementação da estratégia preconizada. De seguida, é importante analisar as expectativas, capacidades, necessidades e níveis de satisfação existentes no grupo de trabalho. Nessa fase, aquilo que constitui a diferença fundamental entre indivíduos carismáticos e não carismáticos reside no facto de os primeiros demonstrarem melhores competências no nível da sensibilidade e acuidade na avaliação das dificuldades existentes, na observação dos recursos e problemas a resolver e na compreensão mais completa das aspirações dos membros do grupo. Essa maior capacidade de análise tem ainda a vantagem adicional de possibilitar o reajustamento das estratégias em fases de maior tranquilidade no trabalho, podendo-se, se for caso disto, criar novos desafios ou exagerar as limitações existentes, de forma a obter-se uma maior motivação e apoio às ideias e objectivos a alcançar.

Os resultados das informações recolhidas constituem elementos importantes para a segunda fase, onde são formulados e articulados os objectivos pelos elementos do grupo. A visão estratégica das metas a atingir representa o ponto fulcral, observando-se a discrepância entre responsáveis carismáticos e não carismáticos pelo tipo de metas que traçam e pela forma como se propõem a atingi-las. Assim, quanto mais idealista e divergente for a proposta apresentada, mais se notará o carisma e, neste sentido, maior será a probabilidade de se desencadear mudança, tanto no estado actual da situação como nos níveis de empenhamento dos outros. Essa ideia acerca da acção do líder levou Conger e Kanungo (1988) a caracterizá-lo como um "construtor de significados", pois a forma como apresenta os novos desafios acaba por condicionar decisivamente o tipo de avaliação obtida pelos outros. Em termos práticos, nessa segunda etapa, as competências mais relevantes relacionam-se com a capacidade de comunicação e de transmissão de uma imagem pessoal de credibilidade e confiança.

Finalmente, na terceira e última fase, o líder centra a sua atenção na exemplificação da forma como pode ser concretizada a "missão" proposta. A sua preocupação deve ser no sentido de desenvolver um sentimento de optimismo quanto à possibilidade de os objectivos serem alcançados e, simultaneamente, conseguir explicar quais as tarefas e acções a assumir por cada um, de forma a evitar-se a descoordenação de esforços. Assim, quem chefia pode optar por recorrer ao seu próprio 
exemplo pessoal e à vontade em assumir riscos como meios para promover a união em torno da sua "visão", tornando-se, uma vez mais, decisiva a sua competência de persuasão e de influência junto do grupo.

Ao encararem-se os comportamentos do líder carismático como passíveis de produzir efeitos, tanto nas organizações como nos indivíduos que delas fazem parte, assume-se que os indicadores da eficácia devem ser encontrados nesses dois domínios. Conger e Kanungo (1998) introduziram como sinais de eficácia no nível organizacional o retorno do investimento efectuado desde que o responsável assumiu funções e o nível de produção atingido. Em termos mais individuais, são apontadas as mudanças nos valores, atitudes e comportamentos dos funcionários. Aquilo que é proposto pelos autores é que os índices de avaliação individuais poderão representar uma fonte mais fidedigna de aferição dos resultados do líder (uma vez que dependem mais da sua acção directa) do que a produtividade final, pois esta estará mais sujeita à performance de outros sectores da organização ou mesmo das próprias oscilações do mercado (nem sempre passíveis de previsão e resolução). Numa tentativa de concretizar fontes de eficácia mais controláveis, os autores propõem no nível do grupo e da organização o aumento dos sentimentos de coesão entre os colaboradores e, inversamente, a diminuição da conflitualidade, devido ao facto de passar a existir uma maior partilha de valores e de objectivos. No que concerne ao domínio individual, podemse constatar alterações positivas em duas áreas: i) uma maior aceitação de quem toma decisões, existindo maior respeito, confiança e satisfação relativamente à forma como é exercido o poder e ii) um forte comprometimento com os objectivos definidos, de que são exemplos o envolvimento na execução das tarefas, os bons índices de rendimento e os sentimentos de desenvolvimento pessoal derivados do facto de estarem a dar o seu melhor e pertencerem àquele grupo e organização.

A partir da formulação do modelo, Conger e Kanungo (1998) enunciaram um conjunto de questões que deveriam ser objecto de melhoria e atenção por parte da investigação futura, nomeadamente, i) o esclarecimento sobre os processos cognitivos subjacentes ao desenvolvimento das representações mentais que os líderes constroem acerca do que deve ser mudado e daquilo que é possível atingir, tratando-se de saber qual a estrutura e o conteúdo da "visão" defendida (deve ser concebida como um conjunto de valores? Ou dirá respeito à definição de uma "missão"? Ou será "simplesmente" o estabelecimento de um conjunto de objectivos desafiantes?); ii) quais os processos implicados na forma como são implementadas as estratégias de intervenção e concretizados os ideais propostos?; iii) qual o papel das situações de crise? - neste nível, é fulcral clarificar se os líderes carismáticos que emergem em momentos de crise apresentarão diferenças significativas para com os seus pares a quem é atribuída a mesma característica em contextos mais estáveis; iv) identifi- 
car quais os factores que contribuem para a atribuição de carisma, tratando-se de saber que tipo de indivíduos têm maior tendência a assinalar esse atributo aos responsáveis e, por último, v) identificar quais os efeitos de quem chefia, não só sobre as organizações onde se encontram, mas também relativamente aos indivíduos com quem contactam directamente, analisando-se as mudanças ocorridas nas atitudes e valores devido à introdução de uma nova visão (ver Gardner, 1999).

Apesar de existirem várias questões em aberto sobre essa abordagem da liderança, sendo certo que algumas delas podem condicionar a aceitação dos pressupostos avançados, a convicção de Conger (1989) é que poucos líderes poderão ser tão fascinantes e produtivos como os carismáticos, pois aquilo que melhor os caracteriza é o facto de serem "mestres em liderar".

\section{O modelo transformacional e transaccional de liderança}

Esse modelo foi construído a partir dos trabalhos realizados por Bass (1985), propondo-se uma versão inicial que dividia a liderança transformacional da transaccional, para depois se avançar com algumas alterações em publicações posteriores, sugerindo-se uma discriminação mais detalhada das várias dimensões da liderança, desde a transformacional até à "laissez-faire" (ver Bass, 1998; Bass \& Avoio, 1993). Assim, o líder transaccional baseia a sua acção na legitimidade e autoridade que the são reconhecidas em termos formais para exercer o poder, representando práticas comuns a enfatização das regras e das normas estabelecidas superiormente e a chamada de atenção para o cumprimento das tarefas previamente definidas. Paralelamente, valoriza-se a obtenção dos objectivos estabelecidos e a criação de um ambiente de concordância e apoio às ideias propostas, podendo ser apontada a utilização dos reforços e punições como "arma" fundamental para a promoção do empenho dos colaboradores e para o controle dos comportamentos indesejáveis. Já no que se refere aos transformacionais, os processos de motivação são fundamentados num apelo a valores morais e ideais superiores que vão além dos interesses de cada um. Assim sendo, atribui-se ao líder uma capacidade para formular e articular uma determinada "visão" para a organização que é reconhecida por todos como merecedora de confiança e apoio.

A partir dessa dupla formulação, o modelo veio então a sofrer uma maior complexificação, distribuindo-se por três áreas, juntando-se um novo domínio caracterizado pela ausência e/ou evitamento da liderança. $\mathrm{Na}$ área transformacional, foram propostas quatro dimensões: i) influência nos ideais ("carisma"): significa o nível mais elevado da liderança transformacional, sendo o responsável percepcionado pelos outros como 
um modelo a seguir, existindo uma grande admiração, respeito e confiança relativamente à sua figura. Assim, é possível observar uma grande identificação entre os membros do grupo e o líder, sendo este descrito como uma pessoa com capacidades extraordinárias, bastante persistente e determinado no seu trabalho; ii) motivação inspiradora: representa a capacidade do líder para fornecer um significado e desafio às tarefas a efectuar, de modo a motivar e inspirar os elementos do grupo. As questões relacionadas com o espírito de equipa, bem como o entusiasmo e o optimismo nas capacidades de todos para se ultrapassarem as dificuldades, são aspectos caracterizadores dessa faceta. Neste caso, quem chefia tende a ser descrito como uma pessoa obstinada, com imensa energia e capacidade de iniciativa, evidenciando uma grande confiança quanto à possibilidade de o grupo ter um futuro melhor; iii) estimulação intelectual: identifica os comportamentos do responsável no sentido de incentivar os outros a serem inovadores e criativos no trabalho, questionando os princípios adoptados, reformulando os problemas existentes e dando novas sugestões sobre a realização das tarefas. Por isso, não existe um ambiente de crítica e de pouca abertura às novas ideias, pois a originalidade é um valor importante promovido pelo líder, que reage com naturalidade ao surgimento de propostas distintas das suas e iv) consideração individual: remete para os relacionamentos individuais dentro do grupo, verificando-se uma preocupação de quem chefia com as necessidades de realização, pessoal e profissional, dos colaboradores.

No nível transaccional, foram avançadas duas áreas distintas. A primeira diz respeito ao reforço contingente, significando a utilização de consequências positivas por parte do líder em face dos bons desempenhos dos membros do grupo. Apesar de essa dimensão poder constituirse como uma área de acção eficaz, ela não é entendida como passível de gerar os mesmos efeitos das quatro áreas anteriores. Tal facto fica a dever-se ao entendimento dessa acção de liderança como sendo baseada numa troca entre algo que o líder pode oferecer perante um determinado comportamento assumido pelos outros, não implicando qualquer transformação de ideais ou de valores. $O$ segundo factor remete para a "intervenção em crise" (proposta de tradução a partir do original "management-by-exception"). Essa dimensão significa que o líder só actua quando as coisas correm mal ou se distanciam do esperado. As acções de correcção ocorrem através de uma atitude de procura e antecipação dos desvios, enganos ou erros dos subordinados na execução das tarefas (intervenção em crise - activa) ou então podem dizer respeito a uma postura mais reservada do responsável, que só toma medidas de resolução dos problemas quando estes efectivamente ocorrem (intervenção em crise - passiva). Os efeitos dessas duas práticas fazem-se sentir na baixa vontade em assumir riscos e inovar por parte dos funcionários, pois eles receiam as reacções negativas de quem chefia. Em termos de 
eficácia, esse factor tende a apresentar piores resultados do que o reforço contingente e, claro, do que todas as dimensões da liderança transformacional.

Por último, a ausência e evitamento do exercício da liderança é representada pela dimensão"laissez-faire",traduzindo-se normalmente por uma ineficácia nos resultados obtidos. Isto significa que, ao contrário da liderança transformacional e transaccional, aqui não é possível encontrar um ambiente de trabalho com objectivos definidos, pois o responsável não assume qualquer plano de acção e adia tomar decisões importantes, ignorando as suas responsabilidades e autoridade. Como referem Bass e Avolio (1999) o estilo"laissez-faire" é simplesmente a negação da liderança.

A partir da formulação dessas dimensões, Avolio e Bass (1988) sugeriram uma combinação das várias facetas da liderança ao longo de dois eixos. Um deles dá-nos indicações acerca dos níveis de eficácia de cada factor, defendendo-se que, à medida que o líder aumenta os seus comportamentos, desde a intervenção em crise (activa) passando pelo reforço contingente até às quatro áreas da liderança transformacional, vão meIhorando progressivamente os resultados obtidos pelos colaboradores e a performance final. $O$ segundo eixo refere-se ao envolvimento do líder na execução das tarefas e na procura de realização dos objectivos traçados, constituindo o reforço contingente o"ponto de corte" que discrimina decisores mais passivos (que são fundamentalmente caracterizados pela intervenção em crise e "laissez-faire") e decisores mais activos, que apresentam um aumento progressivo dos restantes comportamentos.

Assim, o perfil de liderança "óptimo" é aquele que é caracterizado por baixas frequências de "laissez-faire", seguindo-se uma maior utilização dos estilos transaccionais (aumentando da intervenção em crise para o reforço contingente) e, finalmente, a demonstração das áreas transformacionais, que constituem o grosso das acções. Já o perfil "deficitário" ("suboptimal profile") é marcado por uma atitude no sentido inverso, ou seja, o supervisor é alguém que praticamente não assume as suas responsabilidades e não parece ter qualquer estratégia definida, evidenciando poucos ou nenhuns comportamentos nas dimensões transformacionais (Avolio, 1999). O líder mais eficaz é aquele em que predomina a liderança transformacional, seguido dos comportamentos de reforço contingente, da intervenção em crise (activa e depois a passiva) e, em último lugar, o "laissez-faire" (Avolio \& Bass, 1988).

Relacionado com esse conceito de eficácia encontra-se o "efeito do aumento" dos resultados alcançados, sendo defendido que através da avaliação da liderança transformacional é possível conseguir uma predição de outras varáveis como, por exemplo, os níveis de esforço, a performance e a satisfação dos colaboradores. A antecipação mais exacta daquilo que pode ocorrer nessas áreas é, para Bass (1985), uma progres- 
são relativamente àquilo que se conseguia obter através da análise da liderança transaccional. Dito por outras palavras, o autor defende que o "efeito do aumento" dos resultados tende a ocorrer na medida em que os que ocupam posições de poder assumam uma dimensão transformacional no seu relacionamento com os outros, conseguindo que estes obtenham performances acima das suas expectativas iniciais.

Devido aos efeitos positivos produzidos nas capacidades e potencialidades dos colaboradores, existe ainda a possibilidade de o líder ajudar a promover as competências de liderança, dando-se assim o "efeito em cascata" desde os níveis mais elevados de poder até aos responsáveis dos níveis médios e inferiores da hierarquia (Bass, 1985).

Uma última premissa fundamental associada ao modelo refere que, independentemente do contexto cultural ou do país onde as pessoas se encontram, quando lhes pedimos para descreverem os indivíduos que mais as marcaram, observa-se a tendência para emitirem atributos da liderança transformacional e carismática (ver Avolio \& Bass, 1995; Bass \& Avolio, 1989; Offerman, Kenney, \& Wirtz, 1994).

Em síntese, aquilo que distingue os líderes transformacionais é uma capacidade para demonstrarem comportamentos que levam a mudanças positivas em quatro áreas distintas: i) estimulação no sentido de as pessoas adoptarem novas perspectivas acerca do trabalho, valorizando ideais e valores que são comuns a todos; ii) envolvimento de todos na missão e "visão" que o grupo ou a organização pretende concretizar; iii) sentimentos de maior competência e eficácia no trabalho e iv) maior disponibilidade para fazerem sacrifícios e abdicarem de interesses pessoais quando tal se revela necessário (Bass \& Avolio, 1994; Conger, 1999).

\section{As semelhanças e diferenças entre os modelos}

Apesar de esses modelos terem em comum uma nova abordagem no estudo da liderança, centrada nas características e acções de líderes que conseguem mudanças "extraordinárias" nos grupos e pessoas com quem trabalham, existem algumas semelhanças e diferenças que merecem ser realçadas.

Numa reflexão sobre esses aspectos, Conger (1999) refere nove aspectos que, de algum modo, são comuns às acções dos líderes, quer sejam transformacionais ou carismáticos: i) a aceitação da importância da "visão" enquanto fonte de significação e direcção fornecida aos colaboradores; ii) a capacidade de inspirar os outros relativamente à possibilidade de poderem ultrapassar os limites e alcançarem novos objectivos; iii) o facto de o líder representar um modelo a seguir, tanto nos comportamentos que assume como na disponibilidade que demonstra para fa- 
zer sacrifícios pessoais em nome dos ideais estabelecidos; iv) a constante estimulação intelectual no sentido de os membros do grupo questionarem o que está definido e procurarem novas fórmulas de execução das tarefas; v) a capacidade para atribuir uma significação às situações que as tornam algo de comum a todos os envolvidos na situação; vi) o apelo às necessidades e interesses superiores que são benéficos para os participantes no grupo e/ou organização; vii) a utilização de estratégias de fortalecimento das competências e potencialidades dos colaboradores ("empowerment"); viii) a formulação de expectativas elevadas para todos os elementos envolvidos nas tarefas e ix) o desenvolvimento de uma identidade colectiva em que todos os indivíduos se revêem e se sentem envolvidos.

No que concerne às diferenças, Conger (1999) e Conger e Kanungo (1998) assinalam cinco aspectos fundamentais.

Em primeiro lugar, existem divergências entre os autores acerca dos processos subjacentes à identificação dos colaboradores relativamente à figura do líder. Assim, Conger e Kanungo (1998) demonstram uma maior aproximação à formulação original de Weber (1947), pelo facto de se admitir que a influência sentida pelos indivíduos resulta das qualidades extraordinárias do responsável (que constitui assim a principal fonte de identificação); já para Bass e Avolio (1993), deve-se dar uma maior ênfase às capacidades de quem chefia para tornar as tarefas e a própria "visão" como algo de apelativo a todos os participantes num dado grupo ou organização, sendo a sua eficácia traduzida pelo tipo de envolvimento e aceitação que consegue obter dos outros. Esta última perspectiva também é mais próxima do modelo de Shamir, House e Arthur (1993), que salientam a importância da acção de quem lidera no sentido de promover uma identidade e valores colectivos no auto-conceito dos colaboradores.

Uma segunda diferença entre os três modelos prende-se com o facto de Conger e Kanungo formularem o modelo por etapas, defendendo que na fase inicial o líder deve analisar as condições ambientais (avaliação do "status quo"), decorrendo daqui o tipo de "visão" formulada e a articulação que faz das actividades a realizar. Já para as outras duas propostas, não há uma convicção de que esse momento represente um papel tão crucial na identificação dos liderados com as ideias e projectos do responsável.

O terceiro aspecto diferenciador reside na importância que tanto a formulação inicial de House (1977) como a de Conger e Kanungo (1998) atribuem aos processos de gestão da imagem do líder no sentido de transmitir uma ideia positiva sobre as suas capacidades, enquanto que no modelo de Bass e na formulação posterior de Shamir, House e Arthur não se parece privilegiar esse tipo de processos, que são vistos como mais uma estratégia que pode ser utilizada para fomentar a confiança dos membros do grupo acerca das convicções de quem exerce o poder. 
A quarta área diferenciadora reside no facto de Bass descrever mais pormenorizadamente os efeitos produzidos pelo líder, dando relevância não só aos seus comportamentos, mas também à influência exercida nos outros, enquanto que, por exemplo, no modelo de Conger e Kanungo interessa mais a percepção dos subordinados, que, por si só, pode representar uma medida importante do carisma que é atribuído a quem ocupa posições de decisão.

O quinto, e último, ponto relaciona-se com os esforços que Conger e Kanungo têm vindo a demonstrar na compreensão dos aspectos estratégicos da liderança, nomeadamente os processos utilizados pelos responsáveis para avaliar as oportunidades e os constrangimentos existentes no mercado mais vasto em que se insere a organização, representando um interesse ainda pouco presente noutros modelos.

Em síntese, Conger (1999) considera que a evolução dos três modelos permite afirmar que têm vindo a ficar cada vez mais sofisticados, com uma maior sensibilidade para os aspectos contextuais, alargandose assim os níveis de análise da liderança dentro das organizações. Por outro lado, essa evolução tem sido no sentido de os aproximar e não de os distanciar, existindo uma maior influência entre as diferentes ideias defendidas pelos vários autores, dando assim origem a um paradigma "estável" no domínio da liderança.

Finalmente, deve ser salientado o facto de as investigações levadas a cabo nessa "nova" abordagem demonstrarem que esses líderes alcançam maiores níveis de eficácia pessoal e rendimento nas equipas de trabalho, bem como promoverem experiências mais positivas de satisfação, comprometimento e coesão por parte dos membros do grupo/organização (ver Avolio \& Bass, 1988; Bass, 1990; Bass \& Avolio, 1997; Brown \& Dodd, 1999; Doherty, 1997; Gomes, 2005; Podsakoff, MacKenzie, Moorman, \& Fetter, 1990; Rowold, 2007; Yusof, 1998; Zacharatos, Barling, \& Kelloway, 2000). São esses resultados que encorajam a necessidade de incorporar os pressupostos da liderança carismática e transformacional no estudo daqueles que exercem o poder nos mais variados contextos sociais e económicos.

\section{Charismatic and transformational approach: Conceptual models and contributions to the understanding of leadership.}

Abstract: This paper presents a review of the literature written about the charismatic and transformational leadership approaches, stressing the main concepts and conceptual models. We also observe the possibility of applying these contributions in order to understand leadership actions and the relationship between leaders and group members. Lastly, we describe some results obtained until now about the efficacy of charismatic and transformational leaders.

Keywords: Leadership. Social skills. Collective Behavior. 


\section{Une approche charismatique et transformationnel: les modèles conceptuelles et ses contributions à l'exercice du leadership}

Résumé: Cet article présente une révision de la littérature spécialisée en analysant les concepts et les modèles les plus représentatifs. Ensuite, on examine quelques possibilités d'application de ces contributions théoriques dans l'exercice du leadership, envisageant une compréhension plus fine des processus constitutifs de la relation du leader avec les membres du groupe. En conclusion, on décrit certains résultats obtenus jusqu'à présent concernant les études sur les lidérances caractérisées par le charisme et les approches transformationnelles.

Mots-clés: Leadership, Charisme, Transformationnel.

\section{Enfoque carismático y transformacional: modelos concep- tuales y contribuciones para el ejercicio del liderazgo}

Resumen: En este artículo se presenta una revisión de la literatura acerca del enfoque carismático y transformacional del estudio del liderazgo, buscándose analizar sus conceptos principales y los modelos conceptuales más representativos. De igual modo, se analizan las posibilidades de aplicación de dichas contribuciones al ejercicio del liderazgo, ayudando en la comprensión de los procesos inherentes a la relación entre el líder y los miembros del grupo. Por último, se describen algunos resultados que se obtuvieron hasta ahora en el estudio de líderes con características carismáticas y transformacionales.

Palabras-clave: Liderazgo, Carisma, Transformacional.

\section{Referências}

Aaltio-Marjosola, I., \& Takala, T. (2000). Charismatic leadership, manipulation and the complexity of organizational life. Journal of Workplace Learning: Employee Counselling Today, 12, 146-158.

Avolio, B. J. (1999). Full leadership development: Building the vital forces in organizations. London: Sage.

Avolio, B. J., \& Bass, B. M. (1988). Transformational leadership, charisma and beyond. In J. Hunt, H. R. Baliga, H. P. Dachler \& C. A. Schriesheim (Eds.), Emerging leadership vistas. Lexington, MA:D.C. Heath.

Avolio, B. J., \& Bass, B. M. (1995). Individual consideration viewed at multiples levels of analysis: A multi-level framework for examining the diffusion of transformational leadership.Leadership Quarterly, 6, 199-218.

Bass, B.M. (1985).Leadership and performance beyond expectations. New York: The Free Press. 
Bass, B.M. (1990). Bass and Stogdill's handbook of leadership (3rd ed.). New York: Free Press.

Bass, B. M. (1998). Transformational leadership: Industrial, military, and educational impact. New Jersey: Lawrence Erlbaum Associates.

Bass, B. M., \& Avolio, B. J. (1989). Potential biases in leadership measures: How prototypes, leniency, and general satisfaction relate to ratings and rakings of transformational and transactional leadership constructs. Educational and Psychological Measurement, 49, 509-527.

Bass, B. M., \& Avolio, B. J. (1993). Transformational leadership: A response to critiques. In M.M.Chemers \& R. Ayman (Eds.), Leadership theory and research: Perspectives and directions. New York: Academic Press.

Bass, B. M., \& Avolio, B.J. (1994).Improving organizational effectiveness through transformational leadership. Newbury Park, CA: Sage.

Bass, B. M., \& Avolio, B. J. (1997). Full Range leadership development: Manual for the Multifactor Leadership Questionnaire. California: Mind Garden.

Bass, B. M., \& Avolio, B. J. (1999). Training full range leadership: A resource guide for training with the MLQ. California: Mind Garden.

Bennis, W. G., \& Nanus, B. (1985). Leaders: The strategies for taking charge. New York: Harper \& Row.

Brown, F. W., \& Dodd, N. G. (1999). Rally the troops or make the trains run on time: The relative importance and interaction of contingent reward and transformational leadership. Leadership \& Organization Development Journal, 20, 291-299.

Bryman, A. (1992). Charisma and leadership in organizations. London: Sage.

Burns, J. M. (1978). Leadership. New York: Harper \& Row.

Conger, J. A. (1989). The charismatic leader: Behind the mystic of exceptional leadership. San Francisco: Jossey-Bass.

Conger, J. A. (1999). Charismatic and transformational leadership in organizations: An insider's perspective on those developing streams of research.Leadership Quarterly, 10, 145-170.

Conger, J. A., \& Kanungo, R. (1987). Toward a behavioural theory of charismatic leadership in organizational settings. The Academy of Management Review, 12,637-647.

Conger, J. A., \& Kanungo, R. (1988). The empowerment process: Integrating theory and practice. The Academy of Management Review, 13, 639-652.

Conger, J. A., \& Kanungo, R. (1998). Charismatic leadership in organizations. London:Sage. 
Doherty, A. J. (1997). The effect of leader characteristics on the perceived transformational/transactional leadership and impact of interuniversity athletic administrators. Journal of Sport Management, 11, 275-285.

Fiol,C.H.(1999). Charismatic leadership:Strategies for effecting social change. Leadership Quarterly, 10, 449-483.

Gardner, R. A. (1999). Perceptions of leader charisma and effectiveness: The effects of vision content, delivery, and organizational performance. Leadership Quarterly, 10, 345-374.

Gomes, A. R. (2005). Liderança e relação treinador-atleta em contextos desportivos. Tese de Doutoramento, Universidade do Minho, Braga. Disponível em http://hdl.handle.net/1822/3334

House, R.J.(1977). A 1976 theory of charismatic leadership. In J. G. Hunt \& L.L. Larson (Eds.), Leadership: The cutting edge. Carbondale: Southern Illinois University Press.

Howell, J. M., \& Frost, P.J. (1989). A laboratory study of charismatic leadership. Organizational Behavior and Human Decision Processes, 43, 243-269.

Kouzes, O.,\& Posner, B. (1987). The leadership challenge: How to get extraordinary things done in organizations. San Francisco, CA: Jossey-Bass.

Offerman, L. R., Kennedy, J. K., \& Wirtz, P. W. (1994). Implicit theories: Content, structure and generability. Leadership Quarterly, 5, 43-58.

Podsakoff, P. M., MacKenzie, S. B., Moorman, R. H., \& Fetter, R. (1990). Transformational leader behaviors and their effects on followers' trust in leader, satisfaction, and organizational citizenship behaviors. Leadership Quarterly, 1, 107-142.

Rego, A. (1998). Liderança nas organizações: teoria e prática. Aveiro: Universidade de Aveiro.

Rowold,J.(2006).Transformational and transactional leadership in martial arts. Journal of Applied Sport Psychology, 18, 312-325.

Sashkin, M. (1988). The visionary leader. In J. A. Conger \& R. Kanungo (Eds.), Charismatic leadership:The elusive factor in organizational effectiveness. San Francisco: Jossey-Bass.

Shamir, B., House, R. J., \& Arthur, M. B. (1993). The motivational effects of charismatic leadership:A self-concept based theory.Organizational Science, 4, 1-17.

Shamir, B.,Zakay,E., Breinin, E.,\& Popper,M. (1998). Correlates of charisma leader behaviour in military units:Subordinates' attitudes, unit characteristics, and superiors' appraisals of leader performance. Academy of Management Journal, 41, 387-409. 
Shea, C.H.(1999).Charismatic leadership and task feedback: A laboratory study of their effects on self-efficacy and task performance.Leadership Quarterly, 10, 375-397.

Vecchio, R. (1995). Organizational behavior (3rd ed.). Fort Worth:The Dryden Press.

Weber, M. (1947). The theory of social and economic organization. New York: The Free Press.

Weber, M. (1964). The theory of social economic organization. New York: The Free Press.

Weber, M. (1968). Economic and society (Vol. I). New York: Bedminster.

Yukl, G. (1989). Leadership in organizations (2nd ed.). Englewood Cliffs, NJ: Prentice Hall.

Yusof, A. (1998). The relationship between transformational leadership behaviors of athletic directors and coaches' job satisfaction. Physical Educator, 55, 170-176.

Zacharatos, A., Barling, J., \& Kelloway, E. K. (2000). Development and effects of transformational leadership in adolescents. Leadership Quarterly, 11, 211-227. 